\title{
humanidades
}

Revista humanidades

Enero-junio, 2016 • Volumen 6, número 1 • ISSN 2215-3934 • pp. 1-30

\section{Fruta podrida: La reivindicación de la vida y de la muerte desde un cuerpo enfermo, desechado}

DOI: http://dx.doi.org/10.15517/h.v6i1.25112

\section{Teresa Fallas Arias}

Doctora, profesora Catedrática en la Sección de Comunicación y Lenguaje de la Escuela de Estudios Generales de la Universidad de Costa Rica.

Correo electrónico: teresa.fallas@ucr.ac.cr

Todos los derechos reservados. Universidad de Costa Rica. Esta revista se encuentra licenciada con Creative Commons Reconocimiento-NoComercial-SinObraDerivada 3.0 Costa Rica.

Correo electrónico: humanidades@ucr.ac.cr / Sitio web: http://revistas.ucr.ac.cr/index.php/humanidades 


\title{
Fruta podrida: La reivindicación de la vida y de la muerte desde un cuerpo enfermo, desechado
}

\section{Resumen}

Enfrentada a la desmemoria y al olvido, Lina Meruane recrea en la novela Fruta podrida, el drama vivido en Chile con la implementación salvaje de la economía de mercado, sistema que atacó, de manera siniestra, los campos y los cuerpos de los chilenos. En esta obra Meruane desmonta los dispositivos violentos y coercitivos sobre los cuerpos, reivindicando el derecho a la vida y a la muerte, conjetura desde la que se explora esta novela, a partir de las perspectivas teóricas de Michel Foucault y Judith Butler sobre el poder y la desigual valoración de los cuerpos. Crítica de la memoria oficial que absolvió a los culpables de la deScomposición de la sociedad chilena, Meruane se atreve a decir lo indecible desde un cuerpo enfermo que denuncia la red de poderes deshumanizantes del sistema neoliberal-dictatorial-patriarcal, red que controla el territorio y los cuerpos, haciendo de Chile un gran galpón desmemoriado.
Palabras clave: Dictadura, neoliberalismo, poder, corporalidad, deshumanización.

\section{Fruta podrida: The Vindication of Life and Death from a Sick, Discarded Body}

\begin{abstract}
Faced with forgetfulness and lack of memory, Lina Meruane depicts in the novel Fruta podrida [Rotten fruit], the drama lived in Chile with the savage implementation of the market economy, a system that attacked in sinister ways the spaces and bodies of Chileans. In this piece, Meruane disassembles the violent and coercive devices over the bodies, claiming the right to life and death, conjecture from which I explore this novel which I focus from the theoretical perspective of Michel Foucault and Judith Butler, regarding the power and the unequal valuation of the bodies. This is a critique of the official memory that absolved those that were guilty of the decomposition of Chilean society; Meruane dares to speak the unspeakable from an ill body that condemns the network of dehumanizing powers of the neoliberal-dictatorial-patriarchal, network that controls the territory and the bodies, making of Chile a memoryless warehouse.
\end{abstract}

Keywords: Dictatorship, neoliberalism, power, corporality, dehumanization. 
¿Qué oposición podría ofrecer el ámbito de los excluidos y abyectos a la hegemonía simbólica que obligara a rearticular radicalmente aquello que determina qué cuerpos importan, qué estilos de vida se consideran "vida", qué vidas vale la pena proteger, qué vidas vale la pena salvar, qué vidas merecen que se llore su pérdida?

(Butler, 2005, p. 39)

La relación enfermedad y literatura ha sido persistente a lo largo del tiempo y

\section{Introducción}

del espacio. A este nexo se han referido innumerables escritores y escritoras como Susan Sontag en su obra La enfermedad y sus metáforas, lo mismo que el escritor español Francisco Umbral cuando expresa que la enfermedad, como tema literario, aparece desde la antigüedad. De manera semejante discurre la escritora chilena Diamela Eltit, al reconocer que "no es nueva la indagación que se puede hacer entre enfermedad y escritura (...)" (Eltit, 2000, p. 178) y para probarlo explora el tema en algunas de sus narraciones; entre estas, Impuesto a la carne, novela donde articula la enfermedad que aqueja al cuerpo de las protagonistas y con la que sufre el sistema de salud chileno. La relación también ha seducido al escritor chileno Roberto Bolaño, como se percibe en Literatura + Enfermedad $=$ Enfermedad, capítulo de El gaucho insufrible, en el que Bolaño intercala su propia enfermedad con la padecida por los poetas franceses: Baudelaire, Lautréamont, Rimbaud y Mallarmé, para concluir que si escribir sobre la enfermedad, cuando se está gravemente enfermo, es un suplicio: "también puede ser un acto liberador (...) una suerte de liberación" (Bolaño, 2003, p. 136).

Seducida por la relación enfermedad-escritura, la chilena Lina Meruane aborda este tema en el libro Viajes virales. La crisis del contagio global en la escritura del sida, una puesta en escena que se aparta de lo trillado, porque la 
autora recurre a un enfoque de "resistencia crítica al interior de las políticas hegemónicas que han leído la epidemia desde el poder, la clase y el ordenamiento de los cuerpos" (Sutherland, 2013, p. 254). La experiencia literaria la lleva más allá, cuando aborda la diabetes en las novelas Fruta podrida (2007) y Sangre en el ojo (2012), enfermedad que Meruane ha revelado padecer, al ser interpelada sobre esta dolencia. En estas obras, protagonizadas por diabéticas, Meruane ensaya una escritura-travesía donde relaciona su propia enfermedad con la que padece su país, secuela de la dictadura.

En Sangre en el ojo Meruane realiza un "viaje" por su propia enfermedad, al mismo tiempo hace una autopsia de Chile para denunciar el enfrentamiento político-ideológico, por los crímenes y las desapariciones de miles de chilenos que las políticas de perdón y olvido y la amnesia y ceguera oficial dejaron en la impunidad. En Fruta podrida Meruane explora las políticas neoliberales impulsadas el régimen de Pinochet, para resguardar a las corporaciones internacionales que lucraban con la riqueza frutícola y humana de Chile. Este compadrazgo entre la dictadura y la economía de mercado es socavado por las protagonistas de la novela María y Zoila, quienes desobedecen las disciplinas impuestas por la maquinaria del poder, al enfrentar y desmontar los dispositivos violentos y coercitivos sobre los cuerpos, reivindicando el derecho a la vida y a la muerte, conjetura desde la que se analiza Fruta podrida.

En algunas entrevistas Meruane reconoce que, en Fruta podrida, quería experimentar la biopolítica actual, perspectiva que remite a Michel Foucault, específicamente a La voluntad de saber, primer tomo del libro Historia de la sexualidad, donde el teórico francés expone las prácticas de

\section{De biopolíticas y de cuerpos que importan/no importan}


control ejercidas por los estados modernos, para subyugar a los cuerpos y a la población, al intervenir en la reproducción o procreación, en la salud, la higiene y la longevidad.

Constituida por "hospitales, psiquiátricos, cárceles, cuarteles y fábricas" (Han, 2012, p. 25), a la sociedad disciplinaria, planteada por Foucault, "la define la negatividad de la prohibición” (Han, 2012, p. 26), porque además de ser una sociedad represiva, especializada en mandatos, leyes y obligaciones, se caracteriza por recurrir a distintos "modos de dominación, de sumisión, de sujeción” (Foucault, 1995, p. 104). Dicha sociedad dispone de "formas de coerción, esquemas de coacción aplicados y repetidos (...) horarios, empleos de tiempo, movimientos obligatorios, actividades regulares, meditación solitaria, trabajo en común, silencio, aplicación, respeto, buenas costumbres" (Foucault, 1997, pp. 133-134). En ese sentido, no se busca el sujeto de derecho, sino "el sujeto obediente, el individuo sometido a hábitos, a reglas, a órdenes, a una autoridad que se ejerce continuamente en torno suyo y sobre él (...)" (Foucault, 1997, p. 134), un sujeto que, en la novela Fruta podrida, está representado por las mujeres, población sujetada no solo por el sistema de dominación tradicional, sino por el sistema fabril que excluye a las trabajadoras estacionales o temporeras de todo tipo de derechos y garantías laborales.

Además de interesarse en la biopolítica actual, la escritora chilena confiesa su deseo de explorar la mercantilización del cuerpo femenino, cuerpo que en Fruta podrida experimenta el asedio de la dictadura, régimen que dispone de mecanismos represivos para "el control minucioso de las operaciones del cuerpo" (Foucault, 1997, p. 141), legitimando la sujeción 
constante de sus fuerzas e imponiéndole "una relación de docilidadutilidad" (Foucault, 1997, p. 141). Con esa finalidad, el régimen-militardisciplinario-chileno utilizó diferentes dispositivos para disciplinar el cuerpo social, especialmente el de las mujeres, exigiéndoles la adhesión al sistema neoliberal, sin importarle que las corporaciones internacionales contratantes se ensañaran sobre ellas, como también se encarnizó la autoridad médica sobre sus cuerpos, una vez desmantelado el sistema de salud chileno.

La asimetría del poder recreada por Meruane en Fruta podrida pone en cuestión la desigual valoración de los cuerpos, pues mientras unos cuerpos importan otros son prescindibles, postura que dialoga con la teoría de Judith Butler sobre los cuerpos, cuando la teórica señala que "hay cuerpos que importan más que otros” (Butler, 2005, p. 49). Esta perspectiva que además de admitir una lectura temporo-espacial de los cuerpos situadossitiados durante la dictadura chilena, acepta "como punto de partida la noción de Foucault de que el poder regulador produce a los sujetos que controla, de que el poder no solo se impone externamente, sino que funciona como el medio regulador y normativo que permite la formación de los sujetos" (Butler, 2005, p. 49). Un poder deshumanizado y despiadado que generó todo tipo de resistencias: "improbables, espontáneas, salvajes, solitarias, concertadas, rastreras, violentas, irreconciliables, rápidas para la transacción, interesadas o sacrificiales (...)" (Foucault, 1995, p. 116); un enjambre de puntos de resistencia contra-hegemónicos que son detonados, a lo largo de la novela, por Zoila, diabética, harta de una vida de privaciones y prohibiciones. 
Inscrita en los años ochenta, en "tiempos de injusticia legalizada por el mercado" (Lemebel, 2004, p. 116), la novela Fruta podrida registra las políticas de desmantelamiento promovidas por la dictadura de Pinochet, régimen que, desafecto al nacionalismo económico en todas sus formas y promotor del libre mercado, desamparó a la población trabajadora, mientras protegió a las grandes corporaciones internacionales. Por esa vía procedió a cerrar las empresas nacionales, a destruir los sindicatos, a desmantelar el sistema de salud, a eliminar los programas de servicios sociales y a ejercer políticas de inestabilidad y de contención salarial que ejecutó, especialmente, en la fruticultura, agricultura de exportación de gran éxito en la economía chilena.

Con la adopción del neoliberalismo, la fuerza laboral chilena se feminizó (Valdés, 2000, p. 113); las mujeres se constituyeron en el soporte de las exportaciones frutícolas, por lo que sufrieron los efectos perversos de las políticas neoliberales, al ser destinadas por el sistema a una especie de servidumbre que las empujó "hacia una mayor pobreza, más responsabilidades, nuevas formas de migración, nuevas formas de control y violencia” (Suárez, 2000, p. 32), sujeciones denunciadas en Fruta podrida. Es probable que por ser las mujeres la población más afectada, Meruane recurra a miradas femeninas para diagnosticar y descifrar la enfermedad que sufre Chile, malestar originado por la dictadura al adoptar e imponer las políticas neoliberales en el país. Son las dos hermanas protagonistas

\section{La enfermedad se ha instalado en la casa-país}


las que descubren, desde distintos puntos estratégicos, la podredumbre del régimen dictatorial-neoliberal, sistema que los chilenos no pudieron enfrentar, colectivamente, por estar divididos en dos bandos político-ideológicos.

La fragmentación prevalece en la familia chilena, como se aprecia en las protagonistas de Fruta podrida, María y Zoila del Campo, medio-hermanas desunidas por "una enfermedad metida dentro de su propia casa" (Meruane, 2007, p. 28), pues el sistema defensivo de Zoila parece haber experimentado "un golpe de estado, y en su paroxismo se hubiera dedicado a aniquilar las propias células que lo mantienen vivo" (Meruane, 2007, p. 25), percance similar al que padece la población por el golpe ejecutado por Pinochet. Con los padres muertos o desaparecidos, secuela quizá de la nefasta dictadura, María cuida de Zoila, diabética que exige, a lo largo de la novela, el derecho a morir sin interferencia médica, en una época en la que rige la medicina privada, como se percibe en las declaraciones del médico cuando dictamina: "morirse nadie. Sobre mi cadáver se morirá alguien en este hospital. Para qué cree que estamos trayendo tanta máquina, tanta tecnología importada contra la muerte. Para qué desmantelamos el destartalado policlínico y fundamos este gran hospital" (Meruane, 2007, p. 23).

Este alegato del director hospitalario deja al descubierto la aniquilación del sistema de salud chileno, al mismo tiempo que desenmascara las prácticas lucrativas de la medicina privada y las 
intenciones de las empresas médicas por mantener con vida a los clientes, sin importarles su calidad de vida, como la anciana hospitalizada a quien sin reservas le amputaron sus pies y sus muñones: “todo, menos la voluntad (...) Mutilada estaré, decía hacia el final, lúcida, ácida, certera, pero soy una mujer entera ante la muerte. Y los pacientes de la sala común aplaudían. Y el médico (...) se preguntaba en voz alta por qué no le había cortado también la lengua" (Meruane, 2007, p. 62). Este pasaje de la novela muestra tanto la perversión médica, con respecto a sus pacientes, como la resistencia de los enfermos quienes, aún mutilados, desafían al poder médico-empresarial, conscientes de que los médicos ejercen una práctica abusiva, lucrativa y cínica con los enfermos que recurren a la medicina privada.

Ejemplo de lo anterior es la situación de Zoila, a quien su hermana María debe pagarle las consultas y los medicamentos, haciendo grandes sacrificios económicos que la conducen a negociaciones encubiertas con el director del hospital, especialista que trata de calmarla diciéndole: "Que no se inquietara por la plata, la plata era lo de menos y de todos modos podría ir pagando en cuotas, podría compensar los gastos futuros mediante donaciones anuales a la ciencia... La Mayor siguió los ojos metálicos del Médico, ahora fijos en su panza" (Meruane, 2007, p. 29).

De las donaciones anuales a la ciencia, saben las temporeras que han observado las miradas metálicas del médico, a quien juzgan "un 
hombre extraño, obsesivo; que le faltaba una tuerca y algo más, decían las más viejas, que tuviera cuidado, que muchas habían perdido hijos en el hospital y nunca lograron recuperarlos" (Meruane, 2007, p. 23). Las experiencias de "perder" a sus hijos, mientras están internados en el hospital, atormenta a las empleadas del galpón, pesadumbre que aumenta cuando, por precarias condiciones económicas, negocian a sus recién nacidos con representantes de los grandes hospitales metropolitanos. Se ven obligadas, entonces, a la compra-venta ilegal, legalizada por la inmunidad-impunidad que disfrutan las corporaciones internacionales, negociadoras del fruto de los campos chilenos junto con el fruto del vientre de las trabajadoras.

Así se vislumbra en el diálogo entre María y el enfermero cómplice del contrato, que deja en suspenso la delación: "si alguien te delatara...si se descubriera que has colaborado con el hospital... con las criaturas... con la exportación... con..." (Meruane, 2007, p. 108). Los puntos suspensivos en este pasaje y los silencios entre estos personajes ocultan el trasiego de órganos para trasplantes, ninguno se atreve a confesar que los recién nacidos de las temporeras se exportan en los contenedores de las empresas frutícolas.

Así las cosas, Meruane sitúa estratégicamente a las protagonistas. Por un lado, se ubica María que ostenta una especie de rango militar; una agroquímica especializada en combatir las pestes de los frutales, conocedora del juego del libre mercado. Es la portavoz de la 
compañía frutícola y la encargada de disolver las sublevaciones de las empleadas del galpón, a las que amenaza con el despido o las persuade para que levanten el movimiento con "ofertas individuales, ofertas sin compromiso verdadero de la Empresa: medidas estratégicas: pastillitas edulcoradas que solo iban a dividirlas y a romper la huelga (...). La Mayor disolvió la manifestación porque entendía cómo operaba el cansancio, la necesidad, la impaciencia, la extrema fragilidad de las temporeras" (Meruane, 2007, p. 94).

Apoyada por los militares, quienes invadieron el galpón "decididos a resolver por la fuerza la situación que se había desencadenado, fusilando a los perros para dar un ejemplo de lo que les pasaría a ellas si no se comportaban..." (Meruane, 2007, p. 95), María defiende incondicionalmente a la compañía frutera, rehusándose a reconocer el trabajo extenuante de las temporeras que no tienen posibilidades de organizarse, para detener la explotación que ejercen las compañías sobre sus cuerpos, porque los sindicatos fueron desmantelados por las políticas neoliberales, además “estaban solas, solísimas (...) sin sus hombres, sin sus maridos, sin los padres de la prole, porque todos ellos estaban cesantes o alcoholizados" (Meruane, 2007, p. 92).

La aniquilación sindical es simbolizada por Meruane, con la imagen de un viejo arruinado del que cuentan, quienes le conocieron, "trabajaba su propia huerta y dirigía su propio sindicato en la fábrica de calcetines (...) era un hombre lleno de fuerza, un hombre lleno de 
ideas, un líder de reformas, pero ahora es un hombre vaciado y seco" (Meruane, 2007, pp. 51-52). Desaparecidos los sindicatos, Meruane denuncia las condiciones de incertidumbre que sobrellevan las temporeras por la precariedad de sus empleos, por las condiciones en las que trabajan y por el salario fluctuante e imprevisible; experiencia que sufren desde la especificidad de sus cuerpos, cuerpos abusados y encerrados por las alambradas que rodean el campo frutícola, razón para levantarse en huelga aunque el ingeniero de la compañía las intimide por altoparlante "con descontarles cada minuto de cimarra en el baño" (Meruane, 2007, p. 90).

Sin doblegarse ante la amenaza patronal, las temporeras entrelazan sus demandas con el canto del himno nacional: "chillan a viva voz, es tu cielo azulado, a todo el volumen que les permitían los pulmones, y las brizas te cruzan, seguido de una retahíla de reclamos: que les pagaran al menos el sueldo mínimo, que les pusieran sillas porque tenían destrozadas las rodillas, que instalaran hélices en los techos para que de veras circulara la brisa de la patria" (Meruane, 2007, pp. 90-91). Esta puesta en escena de algunos fragmentos del himno nacional chileno en las voces de las temporeras, mezclados con las demandas laborales, evoca la mutilación que hiciera Pinochet de las estrofas condenatorias de tiranos e invasores en los actos oficiales, durante su mandato. Además, podría considerarse una llamada de atención a los "olvidos" de quienes redactaron los manuales educativos chilenos en el período de Concertación, por 
omitir las palabras golpe de estado y dictadura, rehuyendo llamar a las cosas y a los tiranos por su nombre.

Si bien María rompe el movimiento huelguístico, despidiendo a las temporeras más viejas o sustituyéndolas por trabajadoras desinformadas e inexpertas, no logra disciplinar a Zoila, quien se resiste a seguirle el juego; se convierte en una molestia para la Mayor que se arrepiente, una y mil veces, de haberse hecho cargo de ella; de tener que "convivir para siempre con una incurable" (Meruane, 2007, p. 28), a quien contempla, "con la repentina frialdad de su ojo entomólogo" (Meruane, 2007, p. 15), como un bicho recién fumigado.

María recela de la enfermedad "hereditaria, congénita, degenerativa, impredecible" (Meruane, 2007, p. 25) que ha usurpado la casa arrendada y de adobe que ambas comparten; una "casa sitiada por la geometría implacable de los frutales (...) en el callejón sin salida junto al letrero del Ojo Seco" (Meruane, 2007, p. 18), descripción con la que Meruane sugiere el acorralamiento de la casa-país, por el malestar que agobia a la sociedad chilena.

Inmersa en las políticas neoliberales, María es seducida por el lenguaje mercantil cuando se refiere al éxito de la producción frutícola y al negocio en auge de los recién nacidos. Entiende que conforme pasan los años "la demanda de tejidos y de órganos ha sobrepasado la oferta. Y la demanda seguirá aumentando (...) el hospital está 
cambiando, se está especializando en la investigación de todo tipo de trasplantes" (Meruane, 2007, p. 65).

Experta en la caída de los "mercados por regulaciones proteccionistas, por crisis políticas y hasta revoluciones" (Meruane, 2007, p. 65), sabe también que los políticos y empresarios achacan las caídas de la Bolsa a "un ataque extremista, una treta comunista, un insidioso boicot originado en el proteccionismo capitalista" (Meruane, 2007, p. 105), por lo que, conociendo las tácticas político-empresariales, le exige al director del hospital el triple de dinero por adelantado, para mantener funcionando el mercado de órganos, trasiego en el que participan los grandes hospitales, como se vislumbra en los argumentos del médico que teme quedarse rezagado en la competencia de trasplantes. Según él, en:

todas las ciudades del mundo, en este preciso instante, hay personas recibiendo órganos enteros o pedazos de órganos donados por desconocidos (...) Ciudades de donde provienen los médicos cada año, cargados de ideas, protocolos, procedimientos (...) de diapositivas y de mapas con el trazado urbano de Washington, de Melbourne, de Baltimore, mapas de ciudades sobre pobladas de descorazonados como Manchester, o Johannesburgo, Toronto, Nueva York... (Meruane, 2007, p. 86). 
Promotora del libre mercado, María se involucra en las prácticas comerciales, mientras Zoila se niega a seguirle el juego al sistema, situándose en el extremo contrario de su media hermana. Experta desde niña en hospitales, expedientes médicos y diagnósticos, por su condición de diabética, Zoila descubre el destino de los recién nacidos que su hermana y las temporeras trafican con las empresas médicas, para el trasplante de órganos. Por lo anterior, ella repudia el hipotético trasplante de páncreas que le ofrece el Director General, en una oficina cuyas paredes están cubiertas "con importadas vitrinas de aluminio resplandeciente, llenas de grandes botellas y de relucientes órganos embotellados, tan perfectos que parecían plásticos, tan rozagantes que más que órganos humanos parecían frutos en conserva" (Meruane, 2007, p. 22); órganos que tienen gran demanda, según la especialización de "los hospitales extranjeros: Islamabad, la ciudad de los injertos; Sídney y Dublín, sede oficial de los trasplantes de riñón; Edimburgo, de pulmón; y en Nueva Delhi de corazón (...) en Filadelfia o en Nueva York, se especula hace años el primer trasplante de cerebro" (Meruane, 2007, p. 98).

Descubierto el destino de las incontables criaturas, Zoila quebranta los mecanismos del poder con diferentes artimañas, entre estas el boicot contra su hermana y los médicos que comercializan a los recién nacidos y negocian sus órganos. Consciente de poseer "una energía infinita para la resistencia" (Meruane, 2007, p. 71), declara vivir en trincheras opuestas a las de su hermana, porque mientras María "concentra sus esfuerzos en el plan aéreo contra la peste, yo 
intento boicotearla. Industriosamente ella siembra, fertiliza, pare, y negocia; yo empiezo a planear el modo de desarticular toda su empresa" (Meruane, 2007, p. 73). La conspiración de Zoila comienza con el rechazo de implementos facilitados por los médicos, como los "costosos artefactos para medir el azúcar en la sangre" (Meruane, 2007, p. 46). Estos aparatos que podrían facilitarle el control de la diabetes no le interesan, lo que la seduce son "los planos de las ciudades donde trabajan (...) y ellos me donan sus mapas; aceptan marcar con cruces el punto exacto de los hospitales" (Meruane, 2007, p. 46). Una vez provista de los mapas obsequiados por los médicos, Zoila comienza el complot con intenciones de desplegarlo hacia el país del norte donde están los grandes hospitales que mantienen con vida a los recién nacidos, mientras sus órganos son gestionados para experimentos y trasplantes.

Aunque el "operativo venganza" es planeado por Zoila, María se une a la conspiración cuando envenena la fruta, consciente de que la compañía la menosprecia y la explota, como antes lo hizo con su madre María del Campo y con cientos de trabajadoras que laboran extenuantes faenas: "temporeras enguantadas y también enmascaradas que van colocando una manzana y después otra, un racimo tras otro, en bandejas de cartón" (Meruane, 2007, p. 68). Temporeras de las que María intenta diferenciarse al gritar: "Soy la María del Galpón”, “no cualquier María, no una María anónima como todas esas (...) no como las marías temporeras" (Meruane, 2007, p. 24), pues su función en la empresa consiste en que todas las 
frutas crezcan perfectas, "para que apenas amarilleando en la rama cada una de las frutas sea arrebatada de su ciclo, manoseada, interrumpida su maduración, transportada a los galpones, medida, pesada, desinfectada, verificada en un exhaustivo control de calidad" (Meruane, 2007, p. 69). En su empeño por distanciarse de las temporeras, narra la manera en que "había ascendido peldaño a peldaño desde el primer piso hasta el segundo, dejando atrás el rumor y la pestilencia a sudor y a sangre menstrual de las temporeras" (Meruane, 2007, p. 28).

Si bien María realiza un arduo trabajo en la compañía, se percata de que la empresa se aprovecha "de su versatilidad, de su disponibilidad, de su competencia a toda prueba" (Meruane, 2007, p. 103), sin reconocerle su tenacidad por superar los niveles de producción, por haber roto la huelga de las temporeras y por haber aniquilado la mosca de la fruta y otras pestes del campo. Tarde percibe "que era una pieza más dentro de un complejo engranaje (...) comprendió que los beneficios serían siempre para los otros" (Meruane, 2007, p. 173), pues sin ninguna consideración los dueños de la compañía le negaron la firma del añorado contrato, le objetaron los beneficios, se olvidaron incluso de darle un aguinaldo... Ni un solo peso extra le ofrecieron" (Meruane, 2007, p. 103), incumpliendo las promesas, sin valorar que era "la gestora de la cosecha en el Galpón y la gran colaboradora (...) ¡Soy yo quien ha hecho crecer la grandiosa industria de nuestra fruta de exportación!" (Meruane, 2007, p. 112). 
Desencantada por las falsas expectativas monetarias y desmoralizada por haberse aliado al sistema de libre mercado, en el que se negocian los frutos de los campos chilenos con los recién nacidos, María organiza el mayor complot imaginable, al verter unas gotas de cianuro en la fruta "convenientemente inflada con hormonas, encerada y lustrada, envuelta y encajonada (...) miles de cajas envenenadas por una mano experta. Sí: un veneno que atenta contra la seguridad del mundo" (Meruane, 2007, p. 105).

Su venganza se materializa, días después, cuando observa que la fruta regresa "desde los puntos menos previstos tras la clausura de los mercados pequeños y cadenas de supermercados de todo el mundo. La cosecha nacional y el país entero se desgrana (...) Ya empieza a oler a podrido, empieza a sentirse un aire de país en quiebra" (Meruane, 2007, p. 106). La conspiración golpea tanto a las empresas transnacionales, como a la economía nacional, pues "en todos los cajones hay alguna pera envenenada, alguna manzana o ciruela. Son toneladas de fruta con la piel magullada que pronto comenzarán a desintegrarse" (Meruane, 2007, p. 106), según comenta la prensa aliada al sistema.

Consciente de que será acusada de cometer actos terroristas en contra de la compañía, el país y el mundo, María decide suicidarse, ayudada por Zoila, quien percibe la muerte como una liberación, acto que pospone para sí misma porque, aunque la fruta es devuelta, no restituye a los recién nacidos. Por tal razón, resuelve continuar la 
operación venganza en el país del norte, hacia donde se desplaza, imaginariamente, con el dinero de María y su pasaporte, con intenciones de reivindicar la vida-muerte de los niños. Largarme, dice: "Como la fruta de mi hermana, exportarme. Como los órganos del médico, trasplantarme. Como las criaturas en el hospital, desaparecer misteriosamente" (Meruane, 2007, p. 97). "Irme, exportarme, transplantarme entera pero sola. Sola yo con mi cuerpo" (Meruane, 2007, p. 98).

Y ya que ningún científico ha podido aislar el factor causante de su mal y de su indisciplina intenta introducirse, gangrenada, en el país al que quiere corromper, por haber infectado al suyo; infiltrarse en los grandes hospitales con las tijeras podadoras de los frutales, para cortar los cables y cánulas a los que están enchufados los pacientes: "pinchados, drenados, adelgazados, deteriorados, sentenciados a vivir así y sin derecho a discrepar...” (Meruane, 2007, p. 129). 
Los médicos le aseguran a María que mi desobediencia es provocada por un gen hereditario. La desobediencia es otra enfermedad congénita, también irremediable (Meruane, 2007, p. 71).

Fruta podrida, que bien podría llamarse fruta prohibida por desarrollarse en una sociedad disciplinaria en la que se vive con "hambre de todo lo prohibido" (Meruane, 2007, p. 35), se despliega a partir de Zoila, narradora y poeta que abre-cierra los capítulos con poesías que intercala a lo largo de la novela. El juego jugado por Meruane con el nombre de esta protagonista es seductor, porque Zoila se aleja del estribillo manido que, escuchado aquí y allá, destina a la mujer a cumplir con las tareas de ama de casa, para rebelarse contra el sistema al auto-descubrirse como la insumisa, la transgresora, la indisciplinada, la que impugna la maquinaria del poder. La misma que al decir su nombre es confundido con una particularidad suya, percibido así por el viejo sindicalista que la confunde con María o la enfermera que intenta por todos los medios sonsacarle el nombre, sin percatarse que Zoila intenta decirlo sin llegar a completarlo, por la alteración de la conciencia debido a un coma diabético.

Con la variación del estribillo, Meruane desencadena la subversión de Zoila, quien se niega a registrar en los cuadernos de composición "la comida, la dosis, los colores desplegados por las tiras reactivas

\section{Soy la poeta, soy la insumisa, soy la insurrecta...}


en la orina" (Meruane, 2007, p. 41), para saturarlo con palabras sueltas, recortes de noticias y frases de las que emergen poemas, como un acto de rebeldía y de resistencia al poder. Es en estos cuadernos, denominados de deScomposición, donde Zoila se autodescubre: "todos esos cuadernos te han convertido en la especialista en células, en complejos sistemas defensivos, en mutaciones virales y en la resistencia de las bacterias... El lenguaje del organismo es el único que verdaderamente comprendes: ese idioma es tu única lengua y es tu mejor arma de ataque" (Meruane, 2007, p. 124), confidencia con la que Zoila demuestra conocer la enfermedad que ataca su cuerpo, como la que ataca a Chile, país golpeado por un coma diabético, similar a los que atacan su organismo.

En los cuadernos de deScomposición, Zoila fragua una escritura indómita en la que evoca sus traumas y el deterioro de su cuerpo, junto con el descalabro del cuerpo social; una escritura con la que reivindica el derecho a la vida y a la muerte suya y de los recién nacidos, infantes mantenidos con vida por los grandes hospitales, para garantizar los propósitos clínico-mercantiles de la medicina privada. En estos cuadernos Zoila urde una cartografía nomádica de su corporalidad, consciente de que "cada cuerpo está obligado a decir a su manera, con el síntoma de su preferencia, el relato de lo no dicho, lo no llevado a cabo, lo que ha dejado pendiente el cuerpo de su familia dentro del gran cuerpo histórico y social" (Contreras, 2013, p. 2). 
Con sus poesías, injertadas a lo largo de la novela, Zoila hilvana lo no dicho en la sociedad, a través de poemas que parecen ser la continuación de otros dejados atrás o al margen, develándose en partes y contrapartes, al mismo tiempo que destapa la corrupción en su país.

En un primer momento Zoila se observa como una fruta fermentándose por la enfermedad que la tiene tomada y por las violaciones del viejo que desgarran su tierno corazón, como desgarraron también los de "la hermana, la abuela, la madre de todas" (Meruane, 2007, p. 44), las Marías. En otros versos divaga sobre su propia escritura "con su $\mathrm{S}$ intercalada/ entre sustantivos/ esa ese/ descomponiendo mi cuaderno" (Meruane, 2007, p. 55), una ese con la que Meruane juega el juego del lenguaje hablado y escrito en el cuaderno de deScomposición.

Los poemas de Zoila cuestionan el destino de las criaturas que siguieron la ruta de la exportación junto con la producción frutícola, al observar la forma en que los vientres de las Marías se aprestan para una nueva gestación, como se preparan los campos chilenos ante otra temporada de cosechas. Esta reflexión sobreviene durante la duermevela, espacio en el que comienzan a materializarse sus planes reivindicativos cuando narra: "me duermo sobre el mapa/ por ósmosis/ se me mete un país dentro: avanzo por refrigeradas arterias urbanas recorro pasillos embaldosados" (Meruane, 2007, p. 99). Sumida en un coma diabético, Zoila despliega señales que hacen 
pensar en el fracaso de su plan; las sospechas se derivan de su apreciación sobre sí misma cuando percibe su reflejo duplicado en la ventana del avión, en el que supuestamente viaja hacia el norte, como un fantasma que quizá es otra, también cuando dice: "imagino que me infiltro, gangrenada, en esa tierra (...) siempre prometida" (Meruane, 2007, p. 73)

Otros indicios descubiertos en la trama novelística hacen sospechar que la enfermera protagonista de la parte final de la novela, es una reinvención de Zoila quien, con la conciencia alterada por un coma diabético, imagina a la enfermera que intenta sacarla del letargo, en funciones que ratifican el éxito de su complot contra el gran hospital. Con el tiempo entremezclado por el aturdimiento, Zoila reescribe las labores de la enfermera autorizándola y legitimándola, no solo para que confirme el "éxito" de su conspiración de liberar a los recién nacidos a quienes les "han arrebatado la posibilidad de decidir, de ser dueños de su propio destino" (Meruane, 2007, p. 132), sino para que certifique las reformas ocurridas en los hospitales al privatizarse el sistema de salud. Reformas como la indefensión laboral, la carencia de personal y las agotadoras jornadas de trabajo, condiciones que repercuten en los hospitales con "los pasillos llenos de catres, de quirófanos atiborrados e improvisadas camillas para enfermos terminales" (Meruane, 2007, p. 145).

La enfermera imaginada por Zoila se mueve en un tiempo "alterado, desordenado, desquiciado" (Meruane, 2007, p. 139), en el que 
ejecuta diversas funciones, entre estas, impedir los ataques al hospital iniciados desde hacía "diez años (...) incluso desde antes, desde las denuncias por irregularidades" (Meruane, 2007, p. 147).

Conocedora de la maquinaria hospitalaria, por su condición de diabética, Zoila arremete contra el sistema que da de baja a los pacientes de "la unidad de diálisis, a los enfisémicos, a los cancerosos graves, a los diabéticos descompensados y ciegos, a todos los posibles enemigos del preciado capital médico" (Meruane, 2007 , p. 152), como contra el régimen dictatorial por cuanto "el Estado cada vez se interesa menos por los hospitales. Se ha olvidado de los hospitalizados. El Estado es otro anciano deteriorado, con Alzheimer, en coma: sobrevive en estado vegetal, pero ni siquiera podemos desconectarlo (...) está descerebrado" (Meruane, 2007, p. 148). Las acusaciones se renuevan cuando la enfermera, por órdenes del director hospitalario, desaloja a los pacientes que "no entendían por qué les quitábamos las sondas, por qué los sacábamos de la cama, por qué apagábamos los monitores (...) y los desconectábamos de las máquinas" (Meruane, 2007, p. 152).

Es esta enfermera recreada por Zoila la que al altirito cumplió la orden de poner a todos: "a los desnutridos, a los desamparados, a los desahuciados, sin compasión alguna, sin el menor asomo de piedad, en la calle" (Meruane, 2007, p. 153), ajena a las súplicas de los pacientes para que no los abandonaran, apelando al seguro médico. En este operativo sin precedentes, donde los camilleros fueron 
sustituidos por militares, el hospital se convirtió en "un gran mercado humano abierto las veinticuatro horas los siete días de la semana" (Meruane, 2007, p. 160). La prensa no informó sobre esta maniobra, porque los periodistas estaban en "una conferencia orquestada por los asesores del alcalde" (Meruane, 2007, p. 153), porque la Alcaldía es una entidad "tan corrompida como el Estado. La Alcaldía y el Estado son dos instituciones terminales que van a morir abrazadas, como una pareja de enamorados antes de suicidarse" (Meruane, 2007, p. 167), a la sombra del régimen militar.

Inmersa en el delirio, Zoila intenta explicarle a la enfermera la confabulación para obstaculizar el mecanismo hospitalario, cuando comprendió "que la muerte ponía en jaque el sistema productivo. La muerte (...) podía adquirir un significado... un sentido..." (Meruane, 2007, pp. 173-174). La enfermera, defensora del sistema de salud privado, aduce que la historia le resulta inverosímil porque la muerte es inaceptable: "nadie es propietario de su cuerpo, el cuerpo es un bien colectivo" (Meruane, 2007, p. 174).

Enfurecida ante este comentario, Zoila arremete contra la enfermera, quien así expresa el ataque: "comienza a lanzarme palabras como piedras, con toda la potencia de sus pulmones, me escupe pruebas inculpatorias, datos, fechas de terribles errores médicos (...) Asevera que es siempre peor el remedio que la enfermedad. Me da ejemplos que conozco pero que no quisiera recordar" (Meruane, 2007, pp. 176-177). Ejemplos como las inyecciones de insulina para matar a los locos, la talidomida que dejó lisiados a miles de niños y la 
muerte de miles de niños en África, por las vacunas con las que se intentó inmunizarlos de las epidemias.

Ante el aluvión de denuncias y acusaciones por ser "la voz, la mordaza y el placebo del hospital, y a veces también el respirador artificial y el suero" (Meruane, 2007, p. 179), la enfermera se desquita con Zoila descalificando su escritura cuando expresa: "se las da de poetiza o poeta o como se les llame a las escritoras de versos en estos tiempos de corrección poética (...) Tantos versos inútiles, versos que no arreglan nada (...) ¡Poesía! Los poetas harían mejor dedicándose a la enfermería que al menos para algo sirve, ipara salvar vidas!" (Meruane, 2007, p. 183). Un pasaje en el que Meruane pone en cuestión y en escena el alcance de la escritura en las transformaciones sociales, sin que su poética se suspenda, por el contrario, los puntos suspensivos con los que cierra Fruta podrida incorporan nuevos debates en la narrativa de la memoria, como se comprueba en Sangre en el ojo, novela donde impugna la petrificación de la oficialidad en la que campea la desmemoria y el olvido; obra donde la escritora chilena reanuda la relación literatura y enfermedad, la propia y la que corroe a su país.

Enfrentada a la desmemoria y al olvido, Lina Meruane recrea en la novela Fruta podrida el drama vivido en Chile bajo la implementación salvaje de la economía de mercado que atacó, de manera siniestra, los campos y los cuerpos de los recién nacidos, desaparecidos al igual que desaparecieron quienes fueron 
encarcelados, tirados al mar o abandonados en los desiertos, durante la nefasta dictadura. Cuerpos sobre los que aún se mantiene "un duelo en suspenso, inacabado, tensional que deja sujeto y objeto en estado de pesadumbre y de incertidumbre, vagando sin tregua alrededor de lo inhallable del cuerpo y de la verdad que faltan (no están) y que hacen falta (se echan de menos)" (Richard, 2010, p. 44). En Fruta podrida Meruane reivindica la vida y la muerte, al desafiar el sistema desde un cuerpo enfermo que, opuesto a la hegemonía simbólica que determina qué cuerpos importan y qué estilos de vida se consideran vida, se resiste al sistema disciplinario, para demandar que se detenga el tráfico de órganos de los recién nacidos.

Opuesta a la memoria oficial que absolvió a los culpables de la deScomposición de la sociedad chilena, en Fruta podrida Meruane se atreve a decir lo indecible desde un cuerpo enfermo y desechado que denuncia la red de poderes deshumanizantes del sistema neoliberal-dictatorial-patriarcal. Una red que controla el territorio y la corporalidad, en especial los cuerpos de las Marías, mujeres abandonadas por sus compañeros y padres de la prole que, cesantes, alcoholizados y desmoralizados no pueden defenderlas; mujeres que experimentan una especie de orfandad de la que no pueden protegerse pues, a diferencia de María Virgen y Madre cuyo fruto del vientre es bendito, ellas están condenadas a negociar los cuerpos de los recién nacidos con los médicos y con sus empleadores, sin poder refugiarse en la religión, habitus al que se acude cuando todo se derrumba. 
Estas mujeres y sus hijos sufren un desamparo total, porque la única figura religiosa representada en la novela es un cristo que cuelga del espejo del microbús, cristo inmovilizado con ambos pies atravesados por un mismo clavo, especie de marioneta que se bambolea según el vaivén del vehículo; el mismo cristo que años después, continúa balanceándose en el espejo, ajeno a lo que sucede a su alrededor, como distante la jerarquía religiosa chilena, aliada del régimen dictatorial y de la economía de mercado. Un alejamiento similar al de los ciegos que aparecen y reaparecen a lo largo de la novela, tocando sus tarros en las plazas públicas sin ninguna prohibición, porque nadie les teme, ciegos que representan a una sociedad permisiva a la que Meruane fustiga, por permitir que el régimen dictatorial-neoliberal convirtiera a Chile en un gran galpón desmemoriado. 
Bolaño, R. (2003). El gaucho insufrible. Barcelona: Anagrama.

\section{Referencias}

Butler, J. (2005). Cuerpos que importan: Sobre los límites materiales y discursivos del "sexo". Buenos Aires: Paidós.

Brum, E. (4 de agosto de 2015). Muriendo en primera persona. El País. Recuperado de:

http://internacional.elpais.com/internacional/2015/08/04/actualidad /1438705256 875636.html

Contreras, F. (4 de septiembre de 2013). ¿Eres o no Lina Meruane?

[Mensaje de un blog]. Recuperado de:

http://eternacadencia.com.ar/blog/editorial/presentaciones/item/ere s-o-no-lina-meruane.html

Eltit, D. (2000). “Cuerpo y fulgor”. En: Olea. Escrituras de la diferencia sexual. Santiago: LOM Ediciones.

Focault, M. (1995). Historia de la sexualidad, la voluntad del poder, (Tomo 1). México: Siglo XXI.

Focault, M. (1997). Vigilar y castigar: nacimiento de la prisión. D. F., México: Siglo XXI.

Lemebel, P. (2004). Zanjón de la Aguada. Santiago: Seix Barral.

Meruane, L. (2007). Fruta podrida. Santiago: Fondo de Cultura Económica.

Meruane, L. (2012). Sangre en el ojo. San José, Costa Rica: Lanzallamas.

Oyarzún, K. (2000). "Desnaturalizar las diferencias: sexo, cultura, poder”. En: Olea. Escrituras de la diferencia sexual. Santiago: LOM Ediciones.

Richard, N. (2010). Crítica de la memoria (1990-2010). Santiago: Ediciones Universidad Diego Portales.

Suárez, B. et al. (2000). Escribir en femenino. Barcelona: Icaria. 
Sutherland, J. P. (2013). "Cuerpos y desplazamientos en Viajes virales". En Revista Nomadías, 17, pp. 253 a 257. Recuperado de: www.nomadias.uchile.cl/index.php/NOarticle/viewFile29955/3173 3

Valdés, X. (2000). "Modernización, democratización y derechos ciudadanos: Una mirada a la vida privada de los temporeros de la fruta". En: Olea. Escrituras de la diferencia sexual. Santiago: LOM Ediciones.

Recibido: 07-octubre-2015

Aceptado: 20-febrero-2016

Todos los derechos reservados. Universidad de Costa Rica. Esta revista se encuentra licenciada con Creative Commons Reconocimiento-NoComercialSinObraDerivada 3.0 Costa Rica.

Correo electrónico: humanidades@ucr.ac.cr Sitio web: http://revistas.ucr.ac.cr/index.php/humanidades 